\title{
KRONIK
}

\section{Af ya da Adalet: Yeni Mali Af Yasası}

Doç. Dr. Semih Öz - Doç. Dr Dilek Özkök Çubukçu

Türkiye Büyük Millet Meclisinin (TBMM) kurulmasılyla yapılan ilk yasama çalışması vergilendirme ile ilgiliydi. TBMM'nin açılışının ertesi günü 24.4.1920'de 1 no'lu Ağnam Resminin Sabık-ı Misillu Olarak İstifası Hakkında Kanun ile tek maddelik bir düzenleme ile "Ağnam Resmini sabıkı misillu dört misli olarak istifasına" karar verilmiștir1. Bu düzenleme ile Osmanlı Meclisi Mebusanı ăgnam resmine (hayvan vergisi) zam getirerek, bu resmin bazı illerde zamlı bazı illerde eski tarifeye göre alınmasına neden olan düzenlemesinin işgal altında olmayan illerde eski zamsız tarifeyle alınacağını belirtiliyordu ${ }^{2}$. Meclisin ilk kabul ettiği yasanın mali amaç dışında daha çok simgesel bir anlamı ve amacı bulunmaktaydı: Egemenlik İstanbul'dan, Ankara'ya geçmişti. Devletin egemenliğe dayanarak vergi alma konusunda sahip olduğu fiili ve hukuki yetkilerin de bundan böyle TBMM'nce kullanılacağı bu yasa ile vurgulanıyordu. Bu ilk vergi yasasının ardından aynı dönemde ilk vergi affının da yasalaştı̆ğ görülmektedir. TBMM'nin kurulmasından yaklaşı altı ay sonra 29.9.1920 tarihli ve 30 sayılı Yasa 1919 yılı da dahil olarak geriye yürütülerek, geçmiş yıllara ait aşar bedelinden borcu bulunan mültezimlerin ana paradan olan borçlarını 1921 yılı Şubat ayı sonuna kadar tamamen ödemeleri durumunda ödenmemiş borçlarının faizden kaynaklanan kısmının affedileceği düzenlenmiştir ${ }^{3}$. Bu haliyle verginin aslından ziyade ferilerinden kaynaklanan ödenmemiş borçların, son dönemlerde sıkça gördüğümüz "ödeme kolaylığı", "vergi borçlarının yeniden yapılandırılması" ya da "tahsilatın hızlandırılması" olarak isimlendirilen düzenlemelerdeki gibi affa uğratılmış olduğu gözlemlenebilir.

${ }^{1}$ İlham Küsmenoğlu, Cumhuriyet Dönemi Vergi Tarihi I Osmanlı Devleti'nden 1980'e, Ankara Oluş Yayıncılık, 2010, s.179.

${ }^{2}$ Kenan Bulutoğlu, Türk Vergi Sistemi, İstanbul, Batı Türkeli Yayıncılık, 2004, s.11.

${ }^{3}$ Küsmenoğlu, a.g.e., s.333. 
Vergi afları elbette TBMM'nin bu sembolik iki düzenlemesiyle sınırlı kalmamıştır. Yine Cumhuriyet döneminin başlarında bir çeşit sedüler gelir vergisi niteliğindeki kazanç vergisinin yenilenmesi çalışmalarında, eski temettü vergilerine ilişkin ödenmeyen vergi borçlarına ilişkin yeniden yapılandırma düzenlemelerinin ayrıca bir af kanunu ile değil ama yeni Kazanç Vergisi Kanunu kapsamında geçici maddelerde düzenlendiği görülmektedir ${ }^{4}$. Özel vergi affı niteliği taşıyan bu düzenlemeden başka aynı yıl genel bir vergi affının düzenlenerek kabul edildiği görülmektedir. 2566 sayılı Vergi Bakayasının Tasfiyesine Dair Kanun adıyla yayınlanan düzenlemeye göre devlete, il özel idarelerine ve belediyelere ilişkin pek çok vergi, resim ve harçlar ile bunların zamlarının "terkin" edilmesine karar verilmiştir. Daha sonraki tarihlerde 1960 yılına kadar vergi aflarının çoğu özel vergi affı niteliğinde olmuştur 5 . Bunlardan biri vergi tarihimizin en tartışmalı vergilerinden varlık vergisine ilişkindir. 1944 yılında 4305 sayılı Yasaya göre tarhedilen varlık vergilerinin henüz tahsil edilmemiş olan bakiyelerinin tahsilinden vazgeçilmesi Türk vergi sisteminin önemli düzenlemelerinden biridir ${ }^{6}$. Bazı kaynaklar bu dönemde tarh edilen toplam varlık vergisi tutarını 465.384.820 TL olmasına karşılık, bu vergi affi ile terkin edilen varlık vergisi tutarını 109.986.481 TL olarak vermekte ve affın ulaştığı önemli boyuta vurgu yapmaktadır ${ }^{7}$. Ancak bu vergiye ilişkin nicelikten ziyade nitelik sorunları ve verginin uygulamasına ilişkin diğer pek çok konudaki sorunlarının afla çözümlenememesi kısa bir süre sonra verginin kaldırılmasıyla sonuçlanmıştır. 1950'ye kadar olan dönemde, vergi

\footnotetext{
42395 sayllı Kazanç Vergisi Kanunun geçici 1'inci maddesinde 1926, 1927 ve 1928 yıllarında vermiş oldukları temettü vergilerinin üç katını vermek suretiyle mükellefiyetini yerine getirenlerin 755 sayılı Kazanç Vergisi Kanununa göre tarh edilmiş ancak henüz tahsil edilmemiş vergi cezalarının terkin olunacağı düzenlenmiştir. (Bkz. R.G. 25.03.1934, s. 2662)

Resmi Gazete arşivi

http://www.resmigazete.gov.tr/main.aspx?home=http://www.resmigazete.gov.tr/arsiv/ 2662.pdf\&main=http://www.resmigazete.gov.tr/arsiv/2662.pdf) (13.05.2011)

${ }^{5}$ Örneğin arazi vergisi bakayasının affı (3568 sayılı kanun), toprak mahsulleri vergisi artıklarının silinmesi (5050 sayılı kanun) gibi. (bkz. ATO, Vergi Afları Tarihi Raporu, http://www.atonet.org.tr/yeni/index.php? $\mathrm{p}=198 \& \mathrm{l}=1(13.05 .2011)$

${ }^{6}$ 15.3.1944 tarihli ve 4539 sayılı Varlık Vergisi Bakayasının Terkinine Dair Kanunun 1'inci maddesinde 4305 sayılı Yasaya göre tarh edilen varllk vergilerinin henüz tahsil edilmemiş olan bakiyeleri terkin edilir şeklinde düzenlenmiş varlık vergisi affına yer verilmektedir.

${ }^{7}$ Cahit Kayra, Savaş Türiye Varlık Vergisi, İstanbul, Tarihçi Kitabevi, 2011, s.52.
} 
afları ile ilgili düzenlemeler daha çok yürürlükten kaldırılan vergilerden kaldırılan alacakların tahsilinden vazgeçilmesiyle ilgili olmuştur ${ }^{8}$.

1960 yılında Milli Birlik Komitesi tarafından çıkartılan 26.10.1960 tarihli ve 113 sayılı Af Kanunu ile 27 Mayıs 1960 tarihine kadar olan işlenmiş olan suçlar affedilir. Çok geniş kapsamlı bir af kanunu niteliği taşısa da bu kanundaki düzenlemelerin en önemli özelliklerinden biri para cezalarının af kapsamına alınmasına rağmen vergi cezalarının tamamen kapsam dışı bırakılmış olmasıdır9 . 1960-1980 döneminde genel af kanunları ile bazı vergilere ilişkin özel vergi aflarının yasalaştığı görülmektedir ${ }^{10}$

1980'li yıllardan sonra getirilen vergi aflarıyla ilgili düzenlemelerde ise kullanılan yöntemlerin farklılaştığı gözlemlenebilir. Bu dönemde yapılan düzenlemelerin sadece vergi borç ve cezalarının affedilmesinden oluşmayan geniş bir çeşitlilik gösterdiği görülebilir. Örneğin mali milat, (kamu) alacakların(ın) tahsilatlarının hızlandırılması, matrah artırımı yapma karşılığ 1 yükümlülere vergi incelemelerinin dışında kalma olanağı, stok beyanı ve ortaklar cari hesabı ile ilgili düzenlemeler, bazı varlıkların ekonomiye kazandırılması gibi isimlerle ve farklı içeriklerle düzenlenmiş olduğu gözlemlenmektedir. İktidarların bu düzenlemelere başvurma sıklığı ise özellikle son y1llarda artmaktadır. Sadece 2000'li yıllarda bu tür düzenlemeler 2001, 2002, 2004, 2006, 2008, 2009 ve 2010 yıllarında yapılmıştır. Buna göre Türkiye'de neredeyse her yıl vergi affı ile ilgili bir düzenleme yapılır hale gelmiştir. Oysaki bu düzenlemeler getirilirken hemen hemen her defasında, bu düzenlemenin son düzenleme olduğu, bir daha böyle bir düzenleme yapılmayacağı belirtilmekte, borçlu yükümlüler için yapılan düzenlemelerin son firsat olduğu vurgulanmakta ancak hemen ardından yeni bir af kanunu ile durumun sürekli hale gelmesine neden olunmaktadır.

Vergi affına ilişkin son ve güncel düzenleme 6111 sayılı Yasa ile yapılmıştır. 25.2.2011 tarihli ve 1.mükerrer 27857 say1lı Resmi Gazete'de yayımlanan Bazı Alacakların Yeniden Yapılandırılması ile Sosyal Sigortalar Ve Genel Să̆lık Sigortası Kanunu Ve Diğer Bazı Kanun ve Kanun Hükmünde Kararnamelerde Değişiklik Yapılması Hakkında Kanun beş kısımdan, toplam 216 ana madde ve 18 geçici maddeden oluşmaktadır. Yapılan düzenleme o

\footnotetext{
${ }^{8}$ Küsmenoğlu, a.g.e., s.334.

${ }^{9}$ A.g.e., s.645.

${ }^{10}$ Örneğin 1963 yılında spor klüplerinin vergi borçlarının bir defaya mahsus affı ile ilgili kanun, 1970 yılında emlak vergisiyle ilgli vergi affi; 1974 yılında Cumhuriyet'in 50'nci yılı nedeniyle bazı suç ve cezaların affı gibi değişik düzenlemeler mevcuttur. bkz. ATO, Vergi Afları Tarihi Raporu, http://www.atonet.org.tr/yeni/index.php?p=198\&l=1 (13.05.2011)
} 
kadar geniş kapsamlıdır ki Maliye Bakanlı̆̆g-Gelir İdaresi Başkanlığı tanıtım broşüründe Yasayı "Cumhuriyet tarihinin en büyük mali yapılandırması" olarak nitelendirmektedir ${ }^{11}$. Gerekçesinde Yasanın getirilme amacı dışarıda 2008 yılında başlayan finansal krizle bağlantı kurularak dış talebin düşmesi ve buna bağlı mal ve hizmet satış gelirlerindeki azalma, kredi teminindeki güçlükler işletmelerin üretim kapasitelerini tam olarak kullanamamaları ve buna bağlı olarak nakit dengelerinin bozulması sonucunda kamuya olan borçların artması, icra takibine maruz kalan borçluların artması olarak belirtilmektedir ${ }^{12}$. Ancak, bu ekonomik ve mali gerekçe kadar 2011 y1lının genel seçim yılı olmasının bu düzenlemenin diğer bir getiriliş nedeni olduğu konusunda düşünüldüğü de söylenebilir. Nitekim sadece vergi aflarının ya da mali afların seçim dönemlerinden hemen önce ya da hemen sonra siyasi bir tasarruf yöntemi olarak kullanılması oldukça sık rastlanan bir durum haline gelmiştir.

Vergi affi, en yalın ifade ile devletin egemenlik yetkisini kullanarak kamu hizmetlerinin finansmanı için kişilerden aldığı vergi, resim ve harçların tahsilinden ve vergilendirme ödevinin zamanında ve eksik yerine getirilmesi dolayısıyla uyguladığı yaptırımlardan vazgeçmesidir. Vergi afları toplumda farklı şekillerde algılanmakta ve bunların kamu mali sistemine, yükümlü davranışlarına ve genel toplum düzeninin akışına olumlu ve olumsuz etkileri bulunmaktadır. Vergi aflarının olumlu etkisi, özellikle ekonominin kriz dönemlerinden sonra mali zorluk içerisinde bulunan ve gerçekte vergi kaçırma amacı olmayan yükümlülere işlerini toparlaması amacıyla yeni firsatlar verilmesi, yükümlülerin devletle barışması ve önümüzdeki dönemde düzenli vergi öder hale gelmesinin sağlanmasıdır. Ayrıca, af kanunu kapsamında getirilen ödeme kolaylıkları ile devlet vergi gelirlerinde artış beklentisi içine girmekte ve bunun da kamu mali disiplinine ve bütçe açıklarının azalmasına olumlu etkisi bulunmaktadır. Af yasasından önce mali sisteme dahil olmayan yükümlüler, af sayesinde kayıt dış1lıtan kurtularak gelecek dönemlerde sistem içerisinde yer alan vergi süjeleri haline gelebilmektedirler. Buna karşılık olumlu etkilerinin dışında, vergisini zamanında ödemeye gayret eden yükümlülere karşı vergi afları, eşitsiz bir durumun ortaya çıkmasına ve vergi adaletinin sorgulanmasına neden olmaktadır. Vergi affı düzenlemelerinin sıklığı (örneğin son 10 yıllık dönemde hemen hemen her yıl bir vergi affı yasalaşmıştır) yükümlülerde bir sonraki af yasası için beklenti oluşmasına ve bu da devletin

\footnotetext{
${ }^{11}$ Gelir İdaresi Başkanlığı, Bazı Alacakların Yeniden Yapılandırılmasına İlişkin 6111 sayılı Kanun Rehberi, Ankara 2011.

126111 sayılı Yasa Gerekçesi, TBMM http://www.tbmm.gov.tr/develop/owa/tasari_teklif_sd.onerge_ bilgileri?kanunlar_sira_no=87370 [Erişim: 1.5 .2011$]$
} 
normal zamanlarda toplayacağı vergi gelirlerinin azalmasına neden olmaktadır. Af düzenlemeleri, diğer taraftan siyasal iktidarların siyasi yatırım amaçlarına da hizmet edebilmektedir. Cezaların sürekli affedilmesi, kanunlara olan güvenin sarsılmasına ve azalmasına neden olmaktadır ${ }^{13}$. 1982 Anayasasının "vergi ödevi"ni düzenleyen 73'üncü maddesinde vergi yükünün adaletli ve dengeli dağılımının maliye politikasının sosyal amacı olduğu belirtildiği dikkate alındığında vergi affı uygulamalarının, vergi yükünün adaletli ve dengeli dağılımına ne kadar hizmet ettiği tartışmalarını da beraberinde getirmektedir. 1982 Anayasasının 87'nci maddesine göre Türkiye Büyük Millet Meclisi üye tamsayısının beşte üç çoğunluğunun kararı ile genel ve özel af ilânına karar vermeye yetkilidir.

Vergi affı yasalarıyla son dönemde getirilen düzenlemelerin aslında Türkiye'de vergi yasalarında yer alan değişik uygulama alternatifleri de mevcuttur. 6183 say1l Amme Alacaklarının Tahsil Usulü Hakkında Kanunda yer alan tecil ( $m d .48)$, terkin ( $m d .105,106)$ düzenlemeleri ile Vergi Usul Kanunda düzenlenmiş olan cezalarda indirim ( $m d$. 376), pişmanlık ve sslah (md. 371), uzlaşma (ek md.1-ek md.12), terkin (md.115) ve tahakkuktan vazgeçme (mük.md.115) gibi müesseselerin de sürekli af ${ }^{14}$ kapsamında değerlendirilmesi mümkündür.

611 sayılı Yasa kapsama giren kamu alacakları ile ilgili idareler Maliye Bakanlığı, Gümrük Müsteşarlığı, Sosyal Güvenlik Kurumu, il özel idareleri, büyükşehir belediyeleri dahil olmak üzere belediyeler, büyükşehir belediyeleri su ve kanalizasyon idareleri, Hazine Müsteşarlığı, KOSGEB, YURT-KUR, TRT, RTÜK, TEDAŞ ve bağl1 işletmeleri, Organize Sanayi Bölgeleri, TCDD, Tütün ve Tütün Mamulleri Tuz ve Alkol İşletmeleri A.Ş, Çevre ve Orman Bakanlığı, DSİ, Kültür ve Turizm Bakanlığı, Tarım ve Köyişleri Bakanlığı, sulama kooperatifleri ve sulama birlikleri, Vakıflar Genel Müdürlüğü, Toprak Mahsulleri Ofisi, kalkınma ajansları ve Spor-Toto Müdürlügüdür. Buradan anlaşıldığı gibi sadece Maliye Bakanlığı ile sınırlı olmayan ve kamu alacağ niteliğinde alacak tahsilatı yapan pek çok kamu kuruluş ve idaresi ile ilişkilendirilmiştir. Ancak kamu alacağı dışında bu idarelerin bir kısmının özel hukuktan doğan alacaklarının (örneğin tarifeden doğan kullanım bedelleri ve ücretler, kredi borçları, kiralar gibi) da af kapsamında bulunduğu görülebilir. $\mathrm{Bu}$ nedenle bu kuruluş ve idarelerce toplanan ve aşağıda da görülebilen alacaklar da dikkate alındığında son af yasasının oldukça geniş kapsamlı bir

\footnotetext{
${ }^{13}$ Murat Başaran, "6111 sayılı Kanun Düzenlemesi Işs̆ğında Kamu Mali Otoritesi/Hazine ile Vergisel Sorunları Olan Mükelleflere Tanınan Olanaklar”, Vergi Sorunları Dergisi Eki Sayı: 270 Vergi Sorunları Mart 2011, s.6.

${ }^{14}$ Başaran, a.g.m., 7.
} 
mali af niteliği taşıdığı söylenebilir. Mali af kapsamına giren alacaklar ise şunlardır:

-Vergi dairelerince tahsil edilen vergiler ve vergi cezaları, gecikme faizleri, gecikme zamları,

-4458 sayılı Gümrük Kanunu ve ilgili diğer kanunlar kapsamında gümrük yükümlülüğü doğan gümrük vergileri, idari para cezaları, faizler, zamlar ve gecikme zammı alacakları,

-Sosyal Güvenlik Kurumuna bağlı tahsil daireleri sigorta primi, emeklilik keseneği ve kurum karşllığı, işsizlik sigortası primi, sosyal güvenlik destek primi ile bunlara bağlı gecikme cezası ve gecikme zammı alacakları vb

-Ecrimisiller,

-Kaynak Kullanımını Destekleme Fonu alacakları,

-Destekleme ve Fiyat İstikrar Fonu alacaklar1,

-İl özel idarelerinin idari para cezaları, harç ve katılma payı gibi bazı alacakları Belediyelerin vergi, tarifeden doğan ücret ve su alacakları,

-Büyükşehir belediyelerinin su ve atık su alacakları,

-YURT-KUR'un öğrenim kredisi alacakları,

-TRT'nin elektrik payı ve bandrol ücretlerinden kaynaklı alacakları,

-Radyo ve Televizyon Üst Kurulunun özel radyo ve televizyon kuruluşlarının reklam gelirlerinden aldığı pay ile eğitime katkı payı alacakları

-KOSGEB'in desteklerden kaynaklanan alacakları,

-TOBB, TÜRMOB, TİB ve bağlı odalarının oda aidatı alacakları ile avukatların baro kesenekleri ve staj kredisi borçları,

-OSB'nin elektrik, su doğalgaz alacakları ile yönetim aidatları alacakları,

-Kültür ve Turizm Bakanlığının kullandırdığı kredi alacakları,

-Tarım ve Köyişleri Bakanlığının kullandırdığı kredi alacakları ile arazi dağıtımı yapılanların arazi bedelleri,

-Sulama Kooperatifi ve Birliklerinin sulamadan kaynaklanan alacakları

-Kullanım bedelleri hasılatı, ticari kâr payları, arazi tahsis bedeli, ağaçlandırma bedeli, kira bedeli alacakları,

-Vakıflara ait taşınmazlara ilişkin kira alacakları,

-Devlet hesabına okutulanlardan mecburi hizmet yüklenimlerini yerine getirmeyenlerin öğrenim giderlerine ilişkin tazminat tutarları,

-TMO'nun satış bedeli alacakları,

-Kalkınma ajanslarının il özel idaresi ve belediyeler ile Sanayi ve Ticaret odalarından olan alacakları,

-Çevre ve Orman Bakanlığının kullandırdığı kredi alacakları,

-Kültür ve Turizm Bakanlığının kullandırdığı kredi alacakları,

-Tarım ve Köy işleri Bakanlığının kullandırdığı kredi alacakları ile arazi dağıtımı yapılanların arazi bedelleri,

-Sulama kooperatifi ve birliklerinin sulamadan kaynaklanan alacakları, 
-65 Yaşını Doldurmuş Muhtaç, Güçsüz ve Kimsesiz Türk Vatandaşlarına Aylık Bağlanması Hakkında Kanun kapsamında olan alacaklar.

6111 sayılı Yasa ile sağlanan kolaylıklar da kapsamdaki idare ve alacaklar kadar geniş kapsamlı ve çeşitlidir. Örneğin kapsama giren borçlar için vade verilerek yeniden yapılandırılması, yeniden yapılandırılan borçların taksitlendirilerek ödenebilmesi olanağı, yapılandırılan borçların kredi kartıyla ödenebilmesi, yükümlü ile vergi idaresi arasındaki davaların sulh yoluyla çözümü için yapılan indirimler, inceleme ve tarhiyat safhasındaki borçlar için yasadan yararlanılarak ödeme olanağı, matrah ve vergi artırımı ile yükümlülerin geçmiş vergilendirme dönemi ile ilgili olası incelenme ve cezaya muhatap olma risklerinin ortadan kaldırılması, işletmelerdeki mallarını beyan ederek kayıt altına almak isteyen, işletmede olmayan mallarını da herhangi bir ceza ödemeden kayıtlardan çıkarmak isteyen yükümlülere kolaylık sağlanması, pişmanlıkla veya kendiliğinden beyanname vererek vergilerini beyan eden mükelleflerin pişmanlık zammı yerine bu vergilerini enflasyon oranında güncelleyerek ödemesi gibi pek çok değişik yöntemin yasada kullanıldığ1 görülmektedir.

Yasa hükümlerinden yararlanmak isteyen yükümlülerin, ilke olarak, 30 Nisan 2011 ve 31 Mayıs 2011 tarihlerine kadar ilgili idarelere başvurmaları gerekmektedir. Ancak başvuru süresi yönünden de oldukça büyük bir esneklik sağlandığı, daha sonra bu sürelerin yürütme organı tarafindan uzatılmasından da anlaşılmıştır ${ }^{15}$. İdare ile ihtilaflı olan yükümlülerin af düzenlemelerinden yararlanabilmeleri için ihtilaftan vazgeçtiklerini ilgili idareye yazılı olarak bildirmeleri de şekli bir yararlanma koşuludur. Bu nedenle yasa koyucunun mali afla aynı zamanda mevcut uyuşmazlıklarının bir bölümünü azaltmayı planladığ1 da anlaşılmaktadır. Borçlu olan yükümlüler, borçlarını normalde uygulanan gecikme zammı ve/veya gecikme faizi yerine TEFE/ÜFE aylık değişim oranı esas alınarak 18 taksitte 36 aya kadar TEFE/ÜFE tutarı hesaplanarak ödeyebileceklerdir. Bazı alacaklarda bu süre daha uzun olabilmektedir. Bu noktada ise ödemelerin orta-uzun vadeye yayılarak tahsili söz konusu olmakta ve borçlular lehine oldukça önemli bir mali avantaj yaratılmaktadir.

Yasada aynı zamanda belirli bir tutarı aşmayan idari para cezaları yönünden de alacaktan vazgeçme düzenlemeleri mevcuttur. Buna göre 120 TL'ye kadar olan idari para cezalarının tahsilinden vazgeçilmiştir. Bu kapsamda 21.06.1927 tarihli ve 1111 say1l Askerlik Kanunu, 10.06.1983 tarihli ve 2839 sayılı Milletvekili Seçimi Kanunu, 2918 sayılı Karayolları Trafik

\footnotetext{
${ }^{15}$ Başvuru süreleri 2011/1713 sayılı Bakanlar Kurulu Kararıyla bir ay süreyle uzatılmıştır.
} 
• Ankara Üniversitesi SBF Dergisi • 66-2

Kanunu, 2972 say1l Mahalli İdareler ile Mahalle Muhtarliklarl ve Ihtiyar Heyetleri Seçimi Hakkında Kanun, 23.05.1987 tarihli ve 3376 say1l Anayasa Değişikliklerinin Halkoyuna Sunulması Hakkında Kanun, 4925 sayılı Karayolu Taşıma Kanunu ve Nüfus Hizmetleri Kanuna göre kesilen cezaların 120 TL'yi geçmeyenleri terkin edilecektir. Yine bu kapsamda, örneğin aslı 120 TL'ye kadar olan trafik para cezaları da idare tarafından re'sen terkin edilmiştir. Buna karşılık kamuya açık alanlarda sigara içenlerle ilgili para cezaları, bu düzenlemelerin kapsamı dışında tutulmuştur.

Tüm bu düzenlemelerin ardında bıraktığı sorular ise şunlardır: Acaba ardı ardına yapılan mali aflar ve vergi afları yasa gerekçelerinde açıklandığı gibi vergi hasılatına ne gibi olumlu etkide bulunacaktır? Vergiye gönüllü uyumu arttırma, vergi bilincine olumlu katkıda bulunma beklentisi karşılanabilecek midir? Ya da daha önemlisi zaten vergi adaleti ile ilgili olumsuz nitelemenin kaldırılmasına olan etkisi artmış olmamakta mıdır? $\mathrm{Bu}$ soruların aslında bilinen yanıtlarının bu yasa yönünden çok kısa bir sürede alınacağı ve sorunların af gibi palyatif çözümlerle değil kapsamlı reformlarla giderilmesinin daha doğru bir çözüm olacağı düşünülmektedir. 